\title{
Clinicopathologic characteristics, therapy and outcomes of patients with primary ureteral small cell carcinoma: a case series and systematic review of the literature
}

\author{
This article was published in the following Dove Press journal: \\ OncoTargets and Therapy \\ 17 August 2017 \\ Number of times this article has been viewed
}

\author{
Wenlong Zhong* \\ Rongcheng Lin* \\ Lei Zhang \\ Chengyue Jin \\ Xuesong Li \\ Qun $\mathrm{He}$ \\ Kan Gong \\ Zhisong $\mathrm{He}$ \\ Liqun Zhou
}

Department of Urology, Peking University First Hospital, Institute of Urology, Peking University, National Urological Cancer Center, Beijing,

People's Republic of China

*These authors contributed equally to this work
Correspondence: Xuesong Li; Liqun Zhou

Department of Urology, Peking University First Hospital, Institute of Urology, Peking University, National Urological Cancer Center, No 8 Xishiku St, Xicheng District, Beijing, People's Republic of China

Tel +86 I0 83575 I0।

Fax +86 I0 $6655 \quad 1726$

Email pineneedle@sina.com;

zhoulqmail@sina.com
Purpose: The aim of this case series was to review the standard diagnosis and treatment procedures of primary small cell carcinoma (SCC) in our institution and discuss the clinicopathologic characteristics, treatments and outcomes of patients with primary ureteral SCC.

Patients and methods: Patients diagnosed with ureteral SCC in Peking University First Hospital, Beijing, China, from January 2007 to December 2016 were included. In addition, we performed a systematic literature review, in October 2016, on case reports and case series of ureteral SCC. The clinicopathologic characteristics, treatments and outcomes of this rare disease were analyzed.

Results: A total of 32 patients were included in our analysis (4 cases from our institution and 28 cases from the literature). Most patients (71.0\%) were male with an average age of 66.6 years (range 48-80 years). The most common symptoms were hematuria $(n=14,48.3 \%)$ and flank pain $(\mathrm{n}=14,48.3 \%)$. All patients underwent surgery, with 12 (37.5\%) patients undergoing multimodality therapy. Regional or distant recurrences developed in 11 patients, among which only 1 patient had bladder recurrence. The overall median survival of the patients was 17 months, with 1- and 3-year survival rates of $51.9 \%$ and $30.3 \%$, respectively. In a univariate analysis, female $(P=0.009)$, pure $\operatorname{SCC}(P=0.03)$ and advanced T stage $(P=0.04)$ were associated with worse overall survival.

Conclusion: Ureteral SCCs are extremely rare neoplasms with aggressive natural history and poor prognosis. T stage, tumor components and gender may be important factors influencing prognosis. A multimodality treatment is recommended for management. However, further studies are needed to improve the treatment strategy.

Keywords: carcinoma, neuroendocrine, small cell, ureteral carcinoma, systematic review

\section{Introduction}

Small cell carcinoma (SCC), also known as oat cell carcinoma, is a tumor with poor differentiation, highly invasive nature and poor prognosis, which mainly originates from the pulmonary system. Extrapulmonary SCC (EPSCC) is rare. The gastrointestinal and genitourinary systems are the most common sites of EPSCC. ${ }^{1}$ In the genitourinary system, the bladder and prostate are most frequently affected, ${ }^{2}$ while ureteral SCCs are extremely rare.

Due to its rarity, the available knowledge of ureteral SCC is based mainly on limited case reports. To our knowledge, the largest reported series presented 3 cases of ureteral SCC in a study by Miller et al. $^{3}$ In the current study, we conducted a detailed analysis of 4 patients diagnosed with ureteral SCC at our tertiary center over the past 
10 years. In addition, we summarized the published cases and performed a systematic review of the disease.

\section{Patients and methods}

Patients diagnosed with ureteral SCC at the Peking University First Hospital, Beijing, China, from January 2007 to December 2016, were included. All surgical specimens were reviewed by 2 senior pathologists who were blinded to the patients' personal data. Any evidence of pulmonary carcinoma was an exclusion criterion. Data on clinical and pathological characteristics, therapy and oncologic outcome were collected. The 2010 upper tract urothelial carcinoma (UTUC) TNM classification ${ }^{4}$ was used for tumor staging. Written informed consent was obtained from all patients included in the study. This study was approved by the institutional review board of Peking University First Hospital. All procedures performed in studies involving human participants were according to the ethical standards of the institutional and national research committee and with the 1964 Declaration of Helsinki and its later amendments or comparable ethical standards.

\section{Search strategy}

A literature search was performed using the PubMed and Embase database to identify all English articles on primary ureteral SCC, with the text available in full, which were published before October 2016. The search terms "ureter" or "upper urinary tract" and "SCC" or "oat cell carcinoma" or "small cell malignancy" were used. The reference lists of the relevant articles were also searched for additional cases. Two reviewers, independently, selected the patients and performed the data extraction.

\section{Statistical analysis}

Statistical analysis was performed using the SPSS software version 20.0 (IBM Corporation, Armonk, NY, USA). Descriptive data were presented as frequency and percentages. The relationship between preoperative factors and overall survival (OS) was analyzed using the Kaplan-Meier method, and statistical significance was determined using the log-rank test. The Cox proportional hazard model was used for univariate analyses. A 2 -sided $P<0.05$ was taken to indicate statistical significance.

\section{Results}

Out of 508 ureteral tumors collected between January 2007 and December 2016 in our hospital, only 4 cases of primary ureteral SCC were identified (Figure 1). All 4 patients underwent retroperitoneal laparoscopic nephroureterectomy with
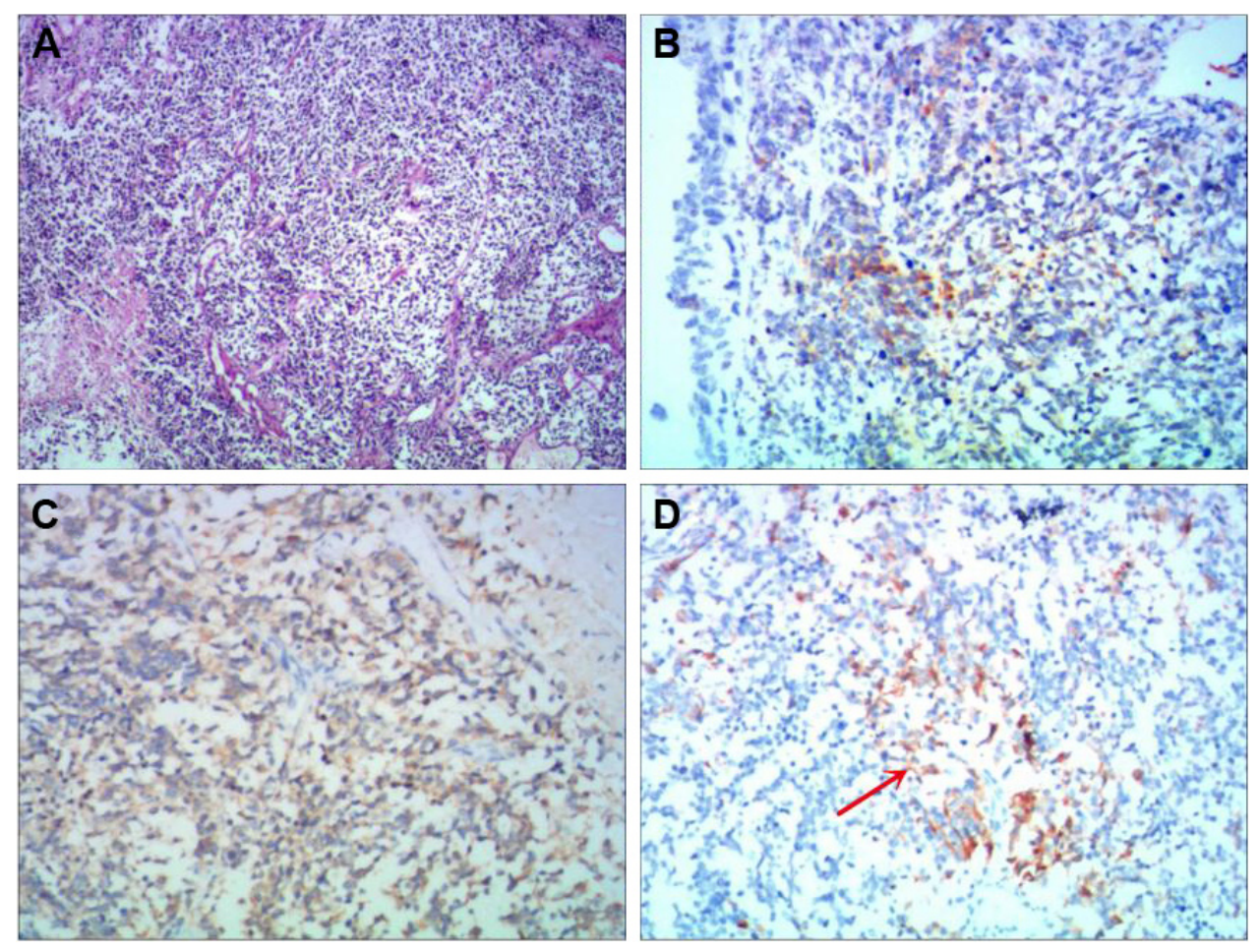

Figure I Histochemical and immunohistochemical examinations of the tumors from our cases.

Notes: (A) SCC showed small and ovoid cells, with hyperchromatic nuclei and scanty cytoplasm (H\&E staining, $\times 400)$. The neoplasm displayed focal expression of CgA (B), strong and diffused expression of Syn (C) and partial, weak to moderate expression of NSE (the red arrow) (D).

Abbreviations: SCC, small cell carcinoma; H\&E, hematoxylin and eosin; NSE, neuron specific enolase; CgA, Chromogranin A; Syn, synaptophysin. 
open distal ureterectomy, by extravesical approach. Baseline characteristics, treatments and outcomes of the 4 cases are summarized in Table 1 . Moreover, 24 publications $^{5-28}$ describing 28 additional cases were identified. Overall, a total of 32 patients were included in our study.

\section{Clinical and pathological characteristics}

Data including demographics, pathological characteristics and treatment plans are summarized in Table 2 . The patients were predominantly male $(\mathrm{n}=22,71.0 \%)$, with an average age of 66.6 years (range 48-80 years). Most patients were Asian $(\mathrm{n}=19,59.3 \%)$, followed by Caucasian $(\mathrm{n}=12,37.5 \%)$. The most commonly reported symptoms were hematuria $(n=14$, $48.3 \%)$ and flank pain ( $n=14,48.3 \%)$. Five out of 12 patients (41.7\%), for which this information was recorded, had a history of tobacco use. The mean tumor size was $3.1 \mathrm{~cm}$ (range $0.5-10.5 \mathrm{~cm})$. The most common location of the tumor was the lower ureteral segment $(\mathrm{n}=16,69.6 \%)$.

Out of 28 patients with available data, 9 (32.1\%) were classified as pT1-2 and 19 (67.9\%) were classified as pT3-4. Four patients (14.3\%) had regional lymph node invasion and only 1 patient (3.6\%) had metastatic disease at the time of diagnosis. For 15 cases (46.9\%), pathological features coexisted with urothelial carcinoma (UC; $n=13,40.6 \%$ ), squamous cell carcinoma $(\mathrm{n}=2,6.3 \%)$, sarcoma $(\mathrm{n}=2,6.3 \%)$, lymphoma $(\mathrm{n}=1,3.1 \%)$, adenocarcinoma $(\mathrm{n}=1,3.1 \%)$ and leiomyosarcoma $(\mathrm{n}=1,3.1 \%)$.

\section{Treatment and prognosis}

Surgery was performed in all patients, with 25 cases (78.1\%) undergoing radical nephroureterectomy (RNU). Among the 32 patients, 12 (37.5\%) underwent multimodality therapy, with the majority of these patients $(n=9)$ receiving platinumbased adjuvant chemotherapy. Three patients underwent nephron-sparing surgery, without adjuvant chemotherapy. Among the 3 patients, 2 developed distant metastases and died at 9 and 7 months after surgery. For the third patient, no disease progression was observed in the subsequent 36 months after surgery. Only 2 patients, preoperatively diagnosed with SCC, were given neo-adjuvant chemotherapy and both of them were alive without progression during a 24- and 38-month follow-up.

The median follow-up time of the 32 patients was 8 months (range 3-82 months). Among the 32 patients, 3 patients had regional recurrence. Ureteral SCC had low urinary tract recurrence (only 1 patient having bladder recurrence at 6 months postoperatively). Eight patients developed distant metastases, with a mean time of 5 months.

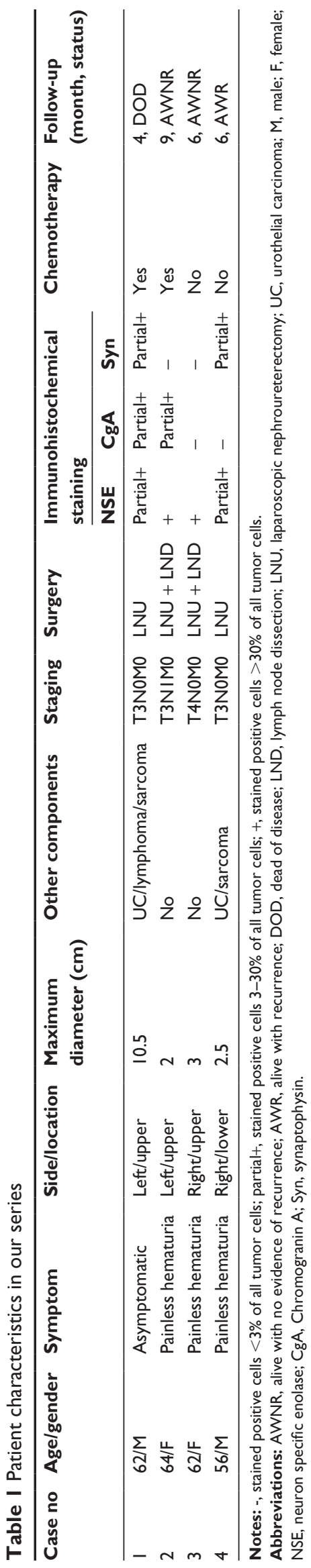


Table 2 Clinicopathologic characteristics and therapy of patients

\begin{tabular}{ll}
\hline Data & $\mathbf{N}(\%)$, median (range) \\
\hline Age (3I available) (years) & $66.6 \pm 8.8(48-80)$ \\
$\geq 65$ & $19(61.3)$ \\
$<65$ & $12(38.7)$ \\
Gender (3I available) & \\
$\quad$ Male & $22(71.0)$ \\
Female & $9(29.0)$ \\
Side (25 available) & \\
Left & $11(44.0)$ \\
Right & $14(56.0)$ \\
Location (23 available) & \\
Upper & $4(17.4)$ \\
Middle & $3(13.0)$ \\
Lower & $16(69.6)$ \\
Histology (32 available) & $17(53.1)$ \\
Pure & $15(46.9)$ \\
Mixed & \\
T stage (28 available) & $9(32.1)$ \\
TI-2 & $19(67.9)$ \\
T3-4 &
\end{tabular}

Abbreviation: RNU, radical nephroureterectomy.

The most common sites of metastasis were the lungs, distant lymph nodes and the liver. Once the metastases developed, the average survival time was less than 2 months.

The overall median survival was 17 months, with 1- and 3 -year survival rates of $51.9 \%$ and $30.3 \%$, respectively (Figure 2A). In the univariate analysis, female $(P=0.009)$, pure SCC $(P=0.03)$ and advanced T stage $(P=0.04)$ were indicators of poor prognosis (Table 3 ). Female patients had a median OS of 7 months compared to 24 months in male patients $(P=0.003$; Figure $2 \mathrm{~B})$. Compared to patients with pure SCC, patients with components of other types of carcinoma had significantly higher median OS (24 vs 10 months, $P=0.04$; Figure 2C). In addition, patients with pT1-2 disease had a higher OS compared to patients with pT3-4 disease $(P=0.02$; Figure 2D). The median survival of patients treated by surgery alone and with adjuvant chemotherapy was 17 and 24 months, respectively. However, no statistical difference was observed in OS between the 2 groups. Interestingly, only 2 cases $(16.7 \%)$ of disease progression were observed in patients receiving adjuvant chemotherapy, compared to 9 patients $(45 \%)$ treated with surgery alone.

\section{Discussion}

Although ureteral SCC was first described over 3 decades ago, ${ }^{6}$ knowledge of this disease is still very limited because of its extremely low incidence. Currently, the natural course of disease and treatment recommendations for ureteral SCC are mainly based on knowledge of pulmonary SCC. To provide a comprehensive overview of available data, we performed an in-depth analysis of 32 cases of ureteral SCC. In our study, we found that the natural history of ureteral SCC differs from that of ureteral UC and that the optimal treatment strategy may be different for the 2 conditions.

Like in the case of UTUC, ${ }^{29}$ most of the patients (90\%) were diagnosed after the age of 50 years, with the peak incidence at the age of 70 years. The neoplasm is 2.4 times more common in males, which is also indistinguishable from UTUC. ${ }^{30}$ Our data have confirmed that the incidence of ureteral SCC is highest in Asian countries, which may be attributed to genetic susceptibility, dietary habits or environmental factors. ${ }^{22}$ Consistent with previous reports, ${ }^{21}$ the most commonly presenting symptoms were gross hematuria and flank pain. To date, no patient presented with paraneoplastic syndrome due to inappropriate hormone secretion.

Concerning the risk factors, previous studies suggested that tobacco exposure might be the principal risk factor for both EPSCC and UTUC. ${ }^{31}$ However, only 8 patients from previous studies were reported smokers and none of our 4 patients had a history of smoking. Although the extent to which tobacco use represents a risk factor remains uncertain, our findings indicate that smoking may not be particularly important for the etiology of ureteral SCC. Hypothetically, ureteral SCC may originate from the multipotent stem cells of the urothelium or intrinsic neuroendocrine cells present in the ureteral urothelium with neuroendocrine differentiation. ${ }^{24}$ Most authors supported the hypothesis that EPSCC originates from multipotent stem cells. ${ }^{32}$ In fact, almost half of the patients $(46.9 \%)$ had other tumor components such as UC and squamous cell carcinoma, which buttresses the hypothesis of the origin of multipotent stem cells.

Much like pulmonary SCC, EPSCC was considered to have an aggressive natural history. ${ }^{1}$ In our study, staging data were available for 28 patients. A total of $21(75.0 \%)$ patients had advanced tumors ( $\geq$ pT3) or regional lymph node invasion at the time of diagnosis. However, the proportion of T4 disease was lower than for EPSCC originating from other sites. ${ }^{33}$ This finding may be related to the early manifestation with gross hematuria and flank pain of ureteral SCC. After radical resection, systemic recurrence was observed in nearly one-third of patients during a relatively short follow-up, indicating that ureteral SCC may be a systemic 

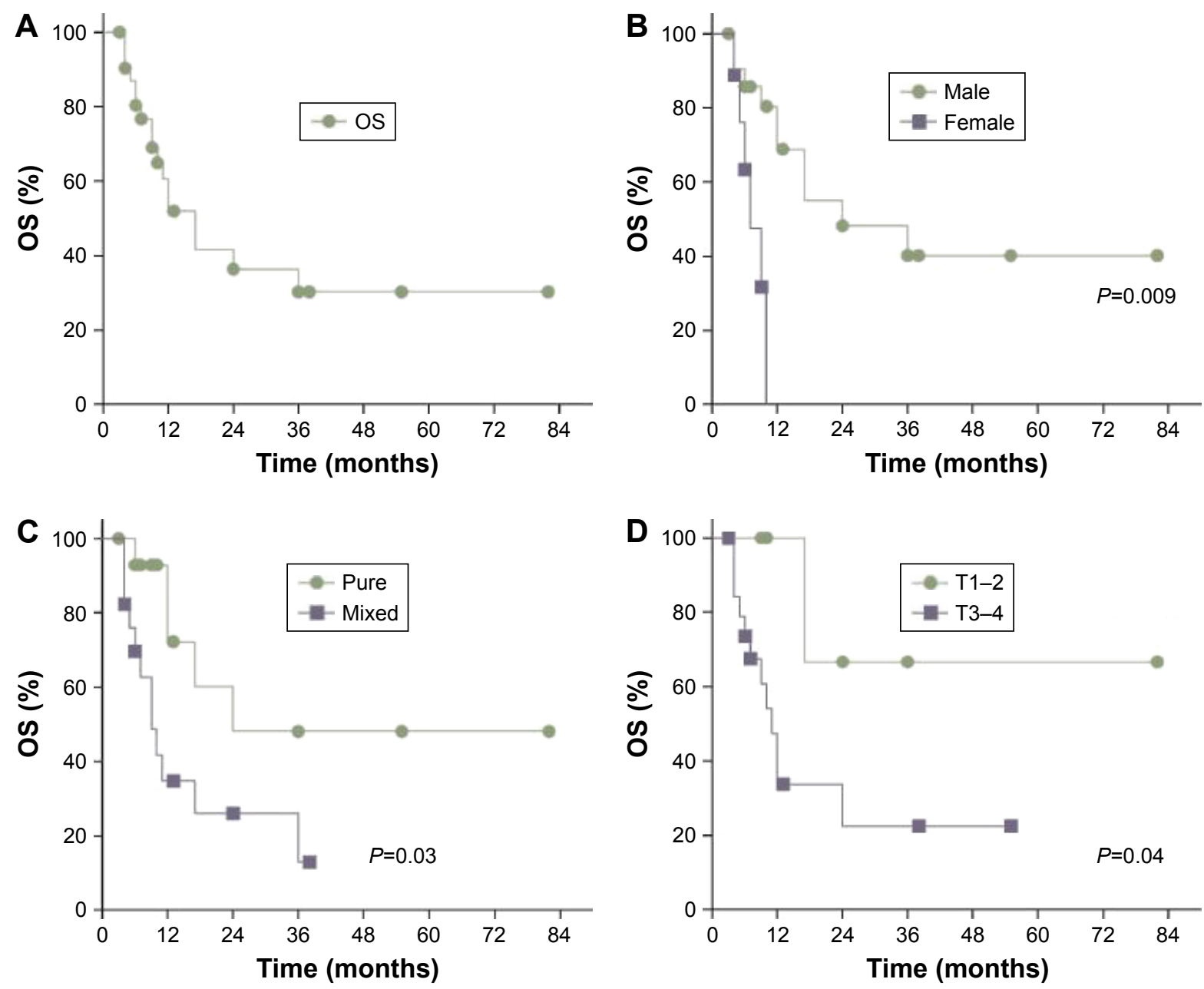

Figure 2 Overall Kaplan-Meier survival curves for patients with ureteral SCC.

Notes: (A) Survival of all patients. (B) Gender-adjusted patient survival. (C) Survival of patients stratified according to tumor components. (D) Survival of patients stratified according to $T$ stage.

Abbreviations: OS, overall survival; SCC, small cell carcinoma.

disease. The bladder recurrence rate of UTUC after RNU ranged from $15 \%$ to $50 \%$, and a single dose of intravesical chemotherapy is recommended postoperatively. ${ }^{34,35}$ However, the bladder tumor recurrence rate of ureteral SCC is much lower than that of ureteral UC; only 1 patient with concomitant UC characteristics had bladder recurrence 6 months postoperatively.

The prognosis of ureteral SCC is poor, with overall 1- and 3 -year survival rates of $51.9 \%$ and $30.3 \%$, respectively. Even the patients with early-stage ureteral SCC (T1-2) have a dismal prognosis. In addition, we noted that female, pure SCC and advanced stage were associated with decreased OS in univariate analysis. Similarly, the pathological stage and pure SCC were worse prognostic factors of bladder SCC. ${ }^{36,37}$ Interestingly, although gender is no longer considered an independent prognostic factor of UTUC,,$^{38}$ our data indicate that female patients with ureteral SCC had a significantly worse OS.
Regarding the disease management, there are no guidelines for EPSCC; thus, treatment has been reported to be modified according to anatomical location. ${ }^{39}$ However, since distinct biological features were shown in ureteral SCC, the treatment strategy for UTUC may not be appropriate for ureteral SCC. Due to the lack of any reliable preoperative evidence of ureteral SCC, our data showed that most cases were initially managed with RNU. Because patients were at high risk for early disease progression following surgery, multimodality treatment, including RNU following adjuvant chemotherapy or chemo-radiation, was frequently chosen. According to our findings, adjuvant chemotherapy appears to reduce the risk of disease progression compared to surgery alone. However, contrary to bladder SCC, it did not significantly influence the OS. Furthermore, since platinum-based chemotherapy was recommended in EPSCC, ${ }^{33}$ the risk of impaired renal function after radical surgery may hinder the application of systemic chemotherapy. 
Table 3 Univariate analysis of prognostic factors for OS of the patients

\begin{tabular}{|c|c|c|c|c|}
\hline \multirow[t]{2}{*}{ Data } & \multirow[t]{2}{*}{$N$ ( $n$ of death) } & \multicolumn{3}{|c|}{ Univariate analysis } \\
\hline & & HR & $95 \% \mathrm{Cl}$ & $P$-value \\
\hline Gender & & 5.769 & I.555-2।.405 & $0.009 *$ \\
\hline Male & $22(11)$ & & & \\
\hline Female & $9(6)$ & & & \\
\hline Age (years) & & 0.352 & $0.112-1.101$ & 0.07 \\
\hline$\geq 65$ & $19(13)$ & & & \\
\hline$<65$ & $12(4)$ & & & \\
\hline Side & & 0.793 & $0.432-1.457$ & 0.46 \\
\hline Left & II (5) & & & \\
\hline Right & $14(8)$ & & & \\
\hline Histology & & 3.144 & $|.099-8.99|$ & $0.03 *$ \\
\hline Mixed & $15(7)$ & & & \\
\hline Pure & $17(11)$ & & & \\
\hline T stage & & 5.047 & $1.098-23.200$ & $0.04 *$ \\
\hline TI-2 & $9(2)$ & & & \\
\hline T3-4 & $19(13)$ & & & \\
\hline Lymph node invasion & & 0.918 & $0.114-7.389$ & 0.94 \\
\hline No & $20(9)$ & & & \\
\hline $\mathrm{N}+$ & $4(2)$ & & & \\
\hline Chemotherapy & & 0.843 & $0.235-3.024$ & 0.79 \\
\hline Yes & $10(4)$ & & & \\
\hline No & $15(10)$ & & & \\
\hline
\end{tabular}

Note: $* P$-value $<0.05$.

Abbreviation: OS, overall survival.

Given the low incidence of urinary tract recurrence of ureteral SCC, nephron-sparing surgery with partial ureterectomy may be an option, to preserve renal function for adjuvant therapy. However, this hypothesis needs to be tested cautiously. Interestingly, 2 patients with neo-adjuvant chemotherapy presented favorable outcomes, without evidence of disease progression during a 24- and 38-month follow-up. Despite the chemotherapy-related toxicity, neo-adjuvant chemotherapy prior to surgery guarantees that the patients considered for surgery receive their course of chemotherapy. Moreover, neo-adjuvant strategies may identify those patients who respond poorly to chemotherapy and are not candidates for surgery. The dilemma stands in that there are few reliable preoperative indicators of ureteral SCC other than biopsy, to aid the diagnosis, while the use of preoperative biopsy for all patients with ureteral tumors is still controversial. ${ }^{40}$

Several limitations of the current review need to be addressed. First, the results have to be viewed cautiously for their retrospective nature and the total number of patients is relatively small. Second, the study is mainly based on individual case reports or small case series, which may cause heterogeneity of diagnosis and management. Finally, we did not perform a multivariate analysis because of the limited available data.

\section{Conclusion}

Ureteral SCCs are extremely rare neoplasms. The limited available data suggest that the disease has an aggressive natural history with poor prognosis. Clinical stage, tumor components and gender may be important factors in determining prognosis. A multimodality treatment approach is recommended. However, further studies are needed to improve the treatment strategy.

\section{Disclosure}

The authors report no conflicts of interest in this work.

\section{References}

1. Brennan SM, Gregory DL, Stillie A, Herschtal A, Mac Manus M, Ball DL. Should extrapulmonary small cell cancer be managed like small cell lung cancer? Cancer. 2010;116(4):888-895.

2. Dakhil CS, Wick JA, Kumar AK, Satyan MT, Neupane P. Extrapulmonary small cell carcinoma: the University of Kansas experience and review of literature. Med Oncol. 2014;31(10):187.

3. Miller RJ, Holmäng S, Johansson SL, Lele SM. Small cell carcinoma of the renal pelvis and ureter: clinicopathologic and immunohistochemical features. Arch Pathol Lab Med. 2011;135(12):1565-1569.

4. Sobin LH, Gospodarowicz M, Wittekind C, editors. Urologic tumors. Renal pelvis and ureter. Classification of Malignant Tumors. 7th ed. New York, NY: Wiley-Blackwell; 2010:161-258. TNM Online.

5. Terada T. Primary small cell carcinoma of the ureter: a case report involving immunohistochemical and molecular genetic analyses of KIT and PDGFRA genes. Pathology. 2009;42(1):101-102.

6. Ordonez NG, Khorsand J, Ayala AG, Sneige N. Oat cell carcinoma of the urinary tract. An immunohistochemical and electron microscopic study. Cancer. 1986;58(11):2519-2530.

7. Tsutsumi M, Kamiya M, Sakamoto M, Tobisu K, Kakizoe T. A ureteral small cell carcinoma mixed with malignant mesodermal and ectodermal elements: a clinicopathological, morphological and immunohistochemical study. Jpn J Clin Oncol. 1993;23(5):325-329.

8. Gupta M, Xia JR, Priminger B, Varkey J, Luke S. Small cell carcinoma of the ureter arising in an adult polycystic kidney disease: a case report. Appl Immunohistochem Mol Morphol. 1999;7(2):164-168.

9. Kim TS, Seong DH, Ro JY. Small cell carcinoma of the ureter with squamous cell and transitional cell carcinomatous components associated with ureteral stone. J Korean Med Sci. 2001;16(6):796-800.

10. Chuang CK, Liao SK. A retrospective immunohistochemical and clinicopathological study of small cell carcinomas of the urinary tract. Chang Gung Med J. 2003;26(1):26-33.

11. Chang CY, Reddy K, Chorneyko K, Kapoor A. Primary small cell carcinoma of the ureter. Can J Urol. 2005;12(2):2603-2606.

12. Busby JE, Brown GA, Tamboli $\mathrm{P}$, et al. Upper urinary tract tumors with nontransitional histology: a single-center experience. Urology. 2006; 67(3):518-523.

13. Martin SM, Gonzalez JR, Lagarto EG, Arteaga CM, Garcia-Ripoll JR, del Busto EF. Primary small cell carcinoma of the ureter. Int $J$ Urol. 2007;14(8):771-773.

14. Su CC, Mak CW, Huan SK. Diagnosis of primary ureteral small cell carcinoma in instrumented urine cytology. Pathology. 2007;39(3):365-367.

15. Banerji JS, Korula A, Panicker JB. Multicentric small cell neuroendocrine neoplasm of the renal pelvis and ureter with concomitant focal high-grade urothelial carcinoma of the ureter: a case report. Indian $J$ Urol. 2008;24(4):571-574.

16. Ryu Y, Kinoshita N, Abe K, Hayashi T. Small cell carcinoma of the ureter with malignant lymphoma: case report and literature review. Acta Med Nagasaki. 2008;53(1):29-32. 
17. Kozyrakis D, Papadaniil P, Stefanakis S, et al. Small cell carcinoma of the urinary tract: a case report. Cases J. 2009;2:7743.

18. Kuroda N, Katto K, Tamura M, et al. Ureteral small cell carcinoma. Med Mol Morphol. 2009;42(1):55-57.

19. Kho VK, Chan PH. Primary small cell carcinoma of the upper urinary tract. J Chin Med Assoc. 2010;73(3):173-176.

20. Miller RJ, Holmang S, Johansson SL, Lele SM. Small cell carcinoma of the renal pelvis and ureter: clinicopathologic and immunohistochemical features. Arch Pathol Lab Med. 2011;135(12):1565-1569.

21. Ouzzane A, Ghoneim TP, Udo K, et al. Small cell carcinoma of the upper urinary tract (UUT-SCC): report of a rare entity and systematic review of the literature. Cancer Treat Rev. 2011;37(5):366-372.

22. Ahsaini M, Riyach O, Tazi MF, et al. Small cell neuroendocrine carcinoma of the urinary tract successfully managed with neoadjuvant chemotherapy. Case Rep Urol. 2013;2013:598325.

23. Carranza OE, Castanon E, Abella LE, et al. Clinical management of small-cell carcinoma of the urinary tract: a 10-year single-center's experience. Clin Genitourin Cancer. 2013;11(2):168-174.

24. Ping JH, Chen ZX, Jiong Q, Han YQ, Nong X. Small cell neuroendocrine carcinoma of the ureter: a case report and literature review. Oncol Lett. 2014;7(3):728-730.

25. Yang J, Zhao Z, Ni J, Dong W, Wang N, Wang B. Urography and CT features of primary small cell carcinoma of the ureter: a case report. Iran J Radiol. 2013;10(3):160-163.

26. Acosta AM, Hamedani FS, Meeks JJ, Wu S. Primary ureteral thyroid transcription factor 1-positive small cell neuroendocrine carcinoma: case report and review of the literature. Int J Surg Pathol. 2015;23(6): 472-477.

27. Osaka K, Kobayashi K, Sakai N, Noguchi S. Successful neoadjuvant chemotherapy for primary invasive small-cell carcinoma of the ureter. Can Urol Assoc J. 2015;9(5-6):E393-E396.

28. Wang W, Liu G, Li Y, Siriwardane U, Ma H. Neuroendocrine carcinoma of the ureter: a case report and literature review. Oncol Lett. 2016; 11(1):257-260.

29. Singla N, Fang D, Su X, et al. A multi-institutional comparison of clinicopathological characteristics and oncologic outcomes of upper tract urothelial carcinoma in China and the United States. J Urol. 2017;197(5): 1208-1213.
30. Shariat SF, Favaretto RL, Gupta A, et al. Gender differences in radical nephroureterectomy for upper tract urothelial carcinoma. World J Urol. 2011;29(4):481-486.

31. Jang H, Yuk SM, Kim JO, Han DS. A rare case of primary malignant small cell carcinoma combined with urothelial cell carcinoma in the ureter. World J Surg Oncol. 2013;11(1):181.

32. Erdem GU, Ozdemir NY, Demirci NS, Sahin S, Bozkaya Y, Zengin N. Small cell carcinoma of the urinary bladder: changing trends in the current literature. Curr Med Res Opin. 2016;32(6):1013-1021.

33. Dores GM, Qubaiah O, Mody A, Ghabach B, Devesa SS. A populationbased study of incidence and patient survival of small cell carcinoma in the United States, 1992-2010. BMC Cancer. 2015;15:185.

34. O'Brien T, Ray E, Singh R, Coker B, Beard R; British Association of Urological Surgeons Section of Oncology. Prevention of bladder tumours after nephroureterectomy for primary upper urinary tract urothelial carcinoma: a prospective, multicentre, randomised clinical trial of a single postoperative intravesical dose of mitomycin $\mathrm{C}$ (the ODMIT-C Trial). Eur Urol. 2011;60(4):703-710.

35. Hagiwara M, Kikuchi E, Tanaka N, et al. Impact of smoking status on bladder tumor recurrence after radical nephroureterectomy for upper tract urothelial carcinoma. J Urol. 2013;189(6):2062-2068.

36. Pasquier D, Barney B, Sundar S, et al. Small cell carcinoma of the urinary bladder: a retrospective, multicenter rare cancer network study of 107 patients. Int J Radiat Oncol Biol Phys. 2015;92(4): 904-910.

37. Ismaili N, Heudel PE, Elkarak F, et al. Outcome of recurrent and metastatic small cell carcinoma of the bladder. BMC Urol. 2009;9:4.

38. Fernandez MI, Shariat SF, Margulis V, et al. Evidence-based sex-related outcomes after radical nephroureterectomy for upper tract urothelial carcinoma: results of large multicenter study. Urology. 2009;73(1): $142-146$.

39. Lee JH, Jeong JS, Kim SR, Lee YC. Small cell carcinoma of the pyriform sinus successfully treated with concurrent chemo-radiotherapy: a case report. Medicine. 2016;95(36):e4759.

40. Luo HL, Kang CH, Chen YT, et al. Diagnostic ureteroscopy independently correlates with intravesical recurrence after nephroureterectomy for upper urinary tract urothelial carcinoma. Ann Surg Oncol. 2013; 20(9):3121-3126
OncoTargets and Therapy

\section{Publish your work in this journal}

OncoTargets and Therapy is an international, peer-reviewed, open access journal focusing on the pathological basis of all cancers, potential targets for therapy and treatment protocols employed to improve the management of cancer patients. The journal also focuses on the impact of management programs and new therapeutic agents and protocols on

\section{Dovepress}

patient perspectives such as quality of life, adherence and satisfaction. The manuscript management system is completely online and includes a very quick and fair peer-review system, which is all easy to use. Visit http://www.dovepress.com/testimonials.php to read real quotes from published authors. 